\title{
A HISTORIOGRAFIA SOBRE O ATO ADICIONAL E OS ENFRENTAMENTOS ENTRE FRAÇÕES LIBERAIS NOS ANOS INICIAIS DA REGÊNCIA
}

\section{THE HISTORIOGRAPHY OF THE ADDITIONAL ACT AND THE CONFRONTATIONS AMONG LIBERAL FRACTIONS IN TH EARLY YEARS OF REGENCY}

\author{
EIDE SANDRA AZEVEDO ABREU*
}

\begin{abstract}
RESUMO
Este artigo problematiza o tratamento dado ao Ato Adicional de 1834 como marco de descentralização política do Império, leitura que se faz presente em parte significativa da historiografia do século XX sobre o século XIX brasileiro. Visto segundo essa perspectiva, o Ato significa a institucionalização das propostas dos liberais "exaltados", atuantes na política brasileira do período. A fim de atingir o objetivo proposto, primeiramente, este estudo mostra como essa historiografia se ancora em memória construída em textos produzidos por políticos que participaram dos fortes enfrentamentos entre os partidos imperiais a partir da década de 1840. Em um segundo momento, o artigo demonstra a possibilidade de entendimento dessa memória como congruente com a visão dos liberais "moderados", opositores dos "exaltados", e a constituição recente na historiografia de uma interpretação não aderida a ela, baseada em exploração minuciosa dos debates do período.
\end{abstract}

PALAVRAS-CHAVE: Ato Adicional de 1834. Brasil Império. Exaltados. Moderados. Descentralização.

\begin{abstract}
This article questions the treatment given to the Additional Act of 1834 as a milestone of political decentralization of the Empire, a reading that is present in a significant part of the historiography of the 20th century regarding 19th century Brazil. Seen from this perspective, the Act would mean the institutionalization of the proposals of the "exalted" liberals, active in Brazilian politics at the period. In order to achieve the proposed objective, this study first shows how this historiography is anchored in formulations of texts produced by politicians who participated in the strong confrontations among the imperial parties that begun in the 1840s. In a second moment the article demonstrates the possibility of understanding of this memory as congruent with the vision of the "moderate" liberals, opponents of the "exalted", and the recent constitution in historiography of an interpretation not adhered to it, based on the detailed exploration of the debates of the period.
\end{abstract}

KEY WORDS: Additional Act of 1834. Brazilian Empire. Exalted and Moderate. Empire. Decentralization.

* Doutora em História pela Universidade Estadual de Campinas (Unicamp). Professora do departamento de Ciências Sociais e do Programa de Pós-graduação em Ciêncais Sociais da Universidade Estadual de Maringá (UEM) - Maringá - Paraná - Brasil. E-mail: eideabreu@uol.com.br 
Introdução

O presente artigo objetiva realizar uma reflexão sobre um dos momentos da história do Império mais significativos e complexos: o da elaboração e aprovação do Ato Adicional de 1834. Iniciamos com a observação de que boa parte da historiografia do século $X X$ sobre a história do Império o considera como marco da descentralização política, isto é, como peça que incorporaria ao quadro institucional o posicionamento dos liberais "exaltados" do início da década de 1830. Por meio da exploração de textos produzidos por políticos do século XIX de diferentes matizes, e que se tornaram fontes daquela historiografia, indicamos a coincidência dessa interpretação com a memória produzida ao longo da história do Império.

A partir de tal constatação, o artigo busca realizar a problematização dessa memória histórica, por meio de textos de jornais e debates do Senado, bem como da exploração de bibliografia recente sobre o período.

\section{O Ato Adicional na historiografia do século XX e a memória política do Império}

É recorrente, nas obras de consagrados historiadores e cientistas sociais do século XX sobre a história do Brasil do século XIX, o estabelecimento de um marco divisor de águas no Ato Adicional de 1834, reforma da Constituição de 1824 interpretada como expressiva da vitória dos liberais mais radicais, que teriam sido propositores da descentralização política consagradora das liberdades locais.

Em A construção da ordem, de 1981, José Murilo de Carvalho considera a descentralização como um resultado direto do Ato Adicional, que, acompanhado do Código do Processo de 1832, teria significado decisivo na vida política do Império:

As consequências da descentralização efetivada pelo Código do Processo Criminal de 1832 e pelo Ato Adicional de 1834 e as rebeliões provinciais da Regência é que iriam, no final da década, possibilitar a formação dos dois grandes partidos que, com alguns altos e baixos, dominaram a vida política do Império até o final. [...] (CARVALHO, 1981, p. 158).

Paula Beiguelman, em obra de 1967, também enfatiza um caráter descentralizador no Ato Adicional, uma vez que considera ter ele significado uma concessão aos liberais exaltados, em virtude "do poder conferido às Assembleias Provinciais":

No plano administrativo, os Conselhos Gerais das Províncias eram transformados em Assembleias Legislativas Provinciais, sendo especificadas suas atribuições de maneira a criar óbices à intervenção do Executivo central. Assim, competia às Assembleias legislar sobre a criação e provimento dos cargos provinciais (artigo 10, §11) que eram definidos de forma a restringir ao máximo a esfera administrativa e política do poder central. [...] (BEIGUELMAN, 1976, p. 53).

Essa associação entre Ato Adicional e descentralização é encontrada mesmo em autores que consideraram uma maior complexidade na dinâmica entre os "poderes

Revista História em Reflexão, Vol. 15, N. 29 | jan. a jun. de 2021 
locais" e "gerais" no período. É o que podemos notar, por exemplo, em Coronelismo, enxada e voto, que Victor Nunes Leal publicou pela primeira vez em 1949. Após sinalizar uma redução dos poderes das câmaras municipais com a lei de $1^{\circ}$ de outubro de 1828, que as teria colocado sob a tutela dos conselhos gerais, dos presidentes das províncias e do Governo Geral, mostra que o Ato Adicional apenas transferiu essa tutela para as então criadas assembleias provinciais. Mas, apesar de fazer esse apontamento, o autor ao mesmo tempo enfatiza o significado descentralizador do Ato Adicional:

O Ato adicional, refletindo uma tendência bastante descentralizadora do ponto de vista das províncias, apenas transferiu para as assembleias provinciais, então criadas, a tensa tutela que sobre as câmaras municipais vinham exercendo os presidentes, os conselhos gerais, o ministro do Império e o parlamento. [...] (LEAL, 1997, p. 93).

Apesar de reconhecer que há "quem considere que a situação dos municípios piorou com a reforma da Constituição", o autor ressalta, ancorando-se na obra de Tavares Bastos, que "no pensamento dos liberais, que a idealizaram, seu principal objetivo era permitir que cada província, atentas às peculiaridades locais, ficasse em condições de estabelecer o regime municipal que lhe fosse mais conveniente" (LEAL, 1997, p. 95-96). Há, no texto de Leal (1997), uma sinalização da existência do ponto de vista municipal, mas é aceito o sentido do Ato do ponto de vista da província, que foi o enfatizado por Bastos na década de 1870.

Essa persistente colocação do Ato Adicional como marco de descentralização, que teria vigorado na maior parte da década de 1830, reproduz a visão que políticos de diferentes matizes formularam, ao elaborarem, a partir da década de 1840, reconstruções históricas sobre o passado político do Império.

Entre tais políticos, o mais citado é Tavares Bastos, por ser muitas vezes considerado como autor que teria sistematizado o projeto liberal de descentralização política do Império'. Na obra A província, que é tida como uma das mais significativas que escreveu, em virtude justamente do projeto de descentralização política nela exposto e defendido, o autor faz uma instrumentalização política explícita da memória da reforma realizada pelo Ato Adicional de 1834. Para entender esse uso, e o sentido político do recurso à bandeira da descentralização por Tavares Bastos em 1870, é importante retomar, pelo menos em largos traços, o percurso que esse político realizou em sua carreira política até então². Ligado inicialmente ao grupo de conservadores (chamados "moderados") que se separou de seu antigo partido para aliar-se aos liberais no início da década de 1860, formando a liga progressista, o 1 Gabriela Nunes Ferreira (1999) o toma como principal referência neste sentido. Ilmar R. Mattos, do mesmo modo que Ferreira (1999), contrapõe à obra do Visconde do Uruguai, Ensaio sobre o direito administrativo, de 1862, a de Tavares Bastos: "No momento que a Historiografia costuma denominar de 'renascer liberal', no último quartel do século XIX, Tavares Bastos aparecia como o principal crítico da centralização imperial e da obra do Visconde do Uruguai, sustentando que a centralização era a causa de quase todos os males do país [...]" (MATTOS, 1987, p. 151). Já Lígia Maria Osório Silva associa Tavares Bastos a Campos Sales; os dois autores têm seus livros tomados por ela como "modelos da aplicação de ideias federalistas para a organização do Estado brasileiro" (SILVA, 1996, p. 75).

2 A exposição do percurso de Bastos (2011) se baseia em meu livro intitulado $O$ evangelho do comércio universal (2011). 
então deputado foi na Câmara o político mais atuante na busca de uma solidificação dessa aliança. Mantendo-se no poder de 1862 a 1868, a liga se mostrava muito frágil, sendo recorrente o questionamento dos liberais em relação à atuação de seus correligionários ex-conservadores, que agiriam no sentido de apenas usá-los para se manter no poder, sem a preocupação de viabilizar a realização de suas propostas, e sem incluí-los em postos políticos importantes. A instabilidade da liga impediu a continuidade de seu exercício do poder, impedimento que se expressou na queda do gabinete Zacarias, em julho de $1868^{3}$.

Conforme pode-se observar em documentos existentes no arquivo pessoal de Tavares Bastos, a circunstância de, a partir de 1868, a liga se encontrar na oposição não unificou as frações que a formavam. As principais lideranças buscaram construir uma unidade por meio da constituição de um novo Partido Liberal, chefiado pelos antigos políticos conservadores moderados ${ }^{4}$, mas tal unidade se mostrava bastante difícil, em razão da resistência de muitos liberais, que tinham viva a memória do exercício recente do poder por tais líderes. Os liberais mais resistentes a manter a aliança com os antigos conservadores passaram a se encaminhar no sentido de se definirem por posições republicanas. É neste contexto que Tavares Bastos formula o projeto de descentralização exposto em A província. O autor afirma com clareza que se trata de recuperar a bandeira da descentralização tendo em vista alargar o programa do novo partido, de modo a solidificar a aliança com os antigos liberais, tentando impedir uma cisão definitiva.

O então ex-deputado, com a intenção de evitar o esvaziamento do novo Partido Liberal pelo afastamento dos chamados liberais "históricos", realiza uma proposta de inclusão imediata da descentralização política no seu programa, descentralização que teria sua "bula de ouro" no Ato Adicional. A associação da proposta atual com esse momento da história passada resultava de uma estratégia explícita de engrandecêla, imanizando-a com a recordação de um momento considerado como marco da atuação dos liberais na história do Império:

[...] Em vez de oferecer reformas sem filiação histórica, preferimos inspirarnos nas tradições de um passado memorável. Em questões que interessam à liberdade, reconhecida e consagrada outrora, mas aniquilada hoje, imensa força tem o partido que clama pela restauração das leis mutiladas. Se faltassem exemplos, o da Hungria contemporânea patentearia a vantajosa posição de um povo que exige, em nome do direito antigo, não em nome somente da teoria política, o restabelecimento de suas instituições esmagadas ${ }^{5}$ (BASTOS, 1937, p. 112-113).

3 Esta foi a explicação que, de acordo com anotações feitas por Bastos, foi dada por Zacarias em reuniões com seus correligionários ligueiros, após a queda do gabinete por ele presidido (COLEÇÃO TAVARES BASTOS, 1.03.33.12, p. 8).

4 Essa documentação vem a ser uma confirmação a mais das descobertas feitas por Célio Ricardo Tasinafo (2003), segundo as quais, nesse momento, o Partido Liberal tinha na grande fragmentação um obstáculo para a sua volta ao governo.

5 Encontramos, aqui, nas palavras do autor, a exposição de um recurso político que foi ressaltado por Marx quando tratou da política europeia, em O 18 Brumário de Luís Bonaparte: o uso da memória do passado para engrandecer o presente. Tratar-se-ia de recurso utilizado nas Revoluções Francesa do século XVIII e Inglesa do século XVII: "A ressurreição dos mortos nessas revoluções tinha, portanto, a finalidade de glorificar as novas lutas e não a de parodiar as passadas; de engrandecer na imaginação 
A historiografia sobre $o$ ato adicional e os enfrentamentos entre frações liberais nos anos iniciais da regência

Bastos (1937) instrumentaliza uma memória dessa reforma da constituição que estava consagrada no imaginário político. A visão do Ato Adicional como marco de descentralização na história do Império já tinha estado presente nos argumentos formulados em panfletos produzidos por políticos liberais e conservadores nas décadas anteriores: Teófilo Otoni, Justiniano José da Rocha e Francisco de Salles Torres Homem (o Timandro) 6 .

Em 1860, o liberal conciliado Teófilo Otoni, na "Circular dedicada aos senhores eleitores de senadores pela província de Minas Gerais", faz uma interpretação do Ato Adicional de modo que, apesar de nele apontar garantias contra a exaltação dos liberais mais radicais, também ressalta nessa reforma ingredientes liberalizantes, entre os quais, as "amplas faculdades" das assembleias legislativas provinciais (OTONI, 1996, p. 214). Otoni, então, afirma ser a reforma resultado de concessões dos liberais moderados aos exaltados:

$\mathrm{O}$ ato adicional era no meu entender uma vitória memorável da democracia pacífica. (...).

$\mathrm{O}$ ato adicional era um penhor da aliança que aos liberais mais adiantados ofereciam os estadistas moderados, senhores da situação. (OTONI, 1996, p. 219-220).

No célebre panfleto "Ação; reação; transação", do jornalista conservador Justiniano José da Rocha, publicado em 1855, o Ato Adicional aparece como resultando da Ação, isto é, como obra da democracia:

[...] a constituição foi reformada no sentido das ideias descentralizadoras e democráticas; criaram-se assembleias legislativas provinciais com direito de estatuir despesas, de decretar impostos, de entender com as circunscrições administrativas e judiciais das províncias, de regular tudo quanto era de sua administração, de ter um exército seu, como um tesouro seu, como uma legislação sua. (ROCHA, 1956, p. 186).

O liberal Timandro, em 1849, faz uma reconstrução da história que pode ser considerada o avesso da feita por Justiniano José da Rocha, mas no panfleto Libelo do povo, então publicado, também faz uma associação do Ato Adicional com uma suposta ampliação das liberdades provinciais, exaltando-o como uma "carta das nossas liberdades provinciais" (TORRES HOMEM, 1956, p. 89).

Conforme vemos, ao longo da história do Segundo Reinado, e em diferentes contextos políticos, foi reiterado o significado do Ato Adicional como reforma consagradora das liberdades provinciais, representando um ápice de descentralização política na história do Império. O sucesso dessa reiteração na cristalização da memória dos acontecimentos do período era, possivelmente, o que dava a Tavares Bastos, em 1870, a segurança da eficácia do seu uso como instrumento para segurar os liberais "históricos" no novo Partido Liberal. E essa memória, como vimos, é reafirmada em obras que estão entre as mais conhecidas e citadas sobre a história do Império.

a tarefa a cumprir, e não de fugir de sua solução na realidade; de encontrar novamente o espírito da revolução e não de fazer o seu espectro caminhar outra vez" (MARX, 1978, p. 8).

6 Conforme Izabel Marson, as obras desses políticos, juntamente com a de John Armitage e a de Joaquim Nabuco, "tornaram-se os mais divulgados relatos dos grandes eventos políticos do Império [...] e acabaram por estabelecer sua memória. [...]" (MARSON,1998, p. 74). 
A historiografia sobre $o$ ato adicional e os enfrentamentos entre frações liberais nos anos iniciais da regência

É possível que essa reiteração aconteça porque a consideração do Ato Adicional como marco de descentralização satisfaz à perspectiva de um olhar distanciado, panorâmico, que abrange uma periodicidade extensa; mas esse vértice perde de vista liames e significados decisivos dos acontecimentos e pode tornar-se cúmplice de procedimentos de construção política da memória histórica que ocultam dimensões significativas dos acontecimentos, reveladoras de divisões e violências presentes na luta política.

Essa reflexão nos é sugerida pelo modo como o Ato Adicional é considerado pelo historiador Paulo Pereira Castro (1967, p. 37), que abordou a história política da década de 1830 em um instigante artigo, tratando os acontecimentos do período de maneira mais minuciosa. No texto deste autor, encontramos, ao invés da consideração do Ato Adicional como tendo ampliado as autonomias locais, uma exposição dessa reforma como tendo significado justamente o contrário. Conforme Castro (1967, p. 37), o Ato Adicional se baseou em limites delineados pela lei de 12 de outubro de 1832, bases essas "que representavam o acordo a que haviam chegado a Câmara dos Deputados e o Senado", e que implicava "a anulação das autonomias locais, com o estabelecimento da tutela das Assembleias Legislativas Provinciais sobre os municípios, tal como o estabeleceria o Ato Adicional” (CASTRO, 1967, p. 38).

O autor, desse modo, ressalta não a amplitude, mas a restrição que significou o Ato Adicional em relação a propostas dos liberais "exaltados", os quais, segundo ele, tiveram que abrir mão da reivindicação de autonomia municipal (CASTRO, 1967, p. 29-30).

O historiador chama a atenção para a desconsideração da questão da autonomia local por um liberal - então um "exaltado" - que seria "de grande coerência ideológica": Teófilo Otoni. Para este político, pareceria "razoável fazer transações quanto a esses pontos, na composição com os moderados", e haveria até motivos de "desconfiança na viabilidade do autogoverno" (CASTRO, 1967, p. 28).

O texto de Castro (1967), pelo contraste que traz à versão predominante acerca do Ato Adicional - versão que o próprio Otoni, como vimos acima, contribuiu para consolidar - instiga à consideração mais detalhada das discussões que se desdobraram na formulação do Ato. Como se posicionavam precisamente as diversas frações liberais que participaram dos debates? O que significou a reforma para cada uma delas? Quais os sentidos que a descentralização política adquiria, de acordo com as posições dos interlocutores no debate?

$\mathrm{Na}$ busca de respostas a estes questionamentos, pesquisamos os debates realizados na Câmara, no Senado e nos jornais da Corte em 1832, ano no qual foi feito o acordo em que se baseou a formulação da Lei de 12 de outubro, que estabeleceu as bases do Ato Adicional.

Federação e Descentralização no embate entre "moderados" e "exaltados" 
Salta à vista, na consideração dos debates de 1832, a dificuldade de delinear com clareza os posicionamentos das diferentes frações liberais, uma vez que as expressões de suas lideranças nem sempre primavam pela coerência, oscilando conforme as alianças e os interesses mais imediatos.

O leitor das obras mais conhecidas sobre o período, habituado a considerar as frações liberais da época como agrupamentos bem delineados em torno de bandeiras bem definidas, logo se surpreende, ao se deparar, por exemplo, com uma semelhança de tom entre Evaristo (liderança dos "moderados") e seu aliado desse momento, Borges da Fonseca (associado aos "exaltados", na bibliografia), no modo de considerar a questão central para os "exaltados", que forçavam a realização de reformas na Constituição: a questão da federação. Houve uma vacilação da parte de Fonseca, que, no número 168 de O Repúblico, datado de 30 de junho de 1832, afirmou que, no país, não cabe federação (p. 603), e, no número 207, de 6 de novembro de 1832, asseverou que a reforma federativa é vital (p. 769).

Ao que parece, em relação à federação, Borges da Fonseca se assemelha ao moderado Evaristo, que, conforme sintetiza Marcello Basile, foi dúbio e oscilante em relação à reforma constitucional: "na condição de deputado, apoiou o projeto Miranda Ribeiro na Câmara, mas, em paralelo, emitia opiniões oscilantes e ambíguas em seu jornal” (BASILE, 2009, p. 77). A posição de Evaristo era compartilhada por uma parte dos moderados. Outros foram "decididamente" favoráveis à reforma. E outros, ainda, foram contra. A maioria dos moderados, como bem observa ainda Basile (2009, p. 77-78), "acabou apoiando as reformas, como denota a rápida passagem do projeto Miranda Ribeiro na Câmara e, por fim, a aprovação do Ato Adicional". Mas isso aconteceu não necessariamente por convicção, mas pela "impossibilidade de resistir à torrente federalista da opinião pública", especialmente vinda das províncias do Norte?

Entretanto, essa concessão não se fez sem um esforço de demonstração de que o sistema "federalista" norte-americano não cabia bem ao Império brasileiro. Com esse intuito, em 10 de fevereiro de 1832, a Aurora reproduz em "Interior" um artigo assinado por Botta (1832, n.p.), texto muito importante porque sinaliza a exclusão dos "exaltados" do poder. O autor argumenta que o sucesso da Revolução Americana ocorreu porque, em primeiro lugar, não havia muita diferença "entre a forma de governo que abandonavam, e a que queriam adotar", uma vez que não estavam saindo de uma monarquia absoluta, e sim de uma monarquia "temperada". Em segundo lugar, o sucesso dever-se-ia à "conduta circunspecta e moderada, de que nunca desvairaram aqueles povos (...)" E continua, assinalando uma inconveniência da aplicação do mesmo sistema norte-americano ao Brasil:

7 Um movimento de adesão paulatina às reformas também foi assinalado por Carlos Eduardo França de Oliveira a respeito do Farol Paulistano, jornal "moderado" de São Paulo: "O acirramento do debate em torno da federação e da reforma constitucional culminou na reestruturação do campo de luta política na imprensa paulista. O Farol Paulistano, que após a abdicação mantivera-se firme no repúdio a qualquer alteração à Cata de 1824, foi aderindo a algumas das reivindicações anteriormente associadas aos 'exaltados'. (...)" (OLIVEIRA, 2009, p. 289). Os moderados teriam, segundo Basile (2009, p. 78), se apropriado da bandeira exaltada. 
(...) raramente apareceram entre eles homens ambiciosos de poder $\mathrm{e}$ dignidade. Não se observou naquele país o aflitivo espetáculo de amigos quebrando os seus antigos laços, e declarando repentina guerra àquele que chegasse a pegar no leme do Estado, sem repartir com eles o poder: o amor da Pátria triunfava da ambição. (...) (AURORA FLUMINENSE, 1832, p. 2507, itálico nosso).

Onde encontramos uma defesa clara e insistente da federação, em 1832, é nos textos publicados por Cipriano Barata que, contudo, não expõe com precisão a forma a ser adquirida pelo preconizado "governo federativo". Defende, na Sentinela da Liberdade de 7 de janeiro de 1832, a

\begin{abstract}
federação verdadeira para cada província cuidar da [ilegível] prosperidade e não ser pisada por aqueles que só querem o [ilegível] e o luxo de um punhado de aristocratas de chinelo, [ilegível] que se esforçam em desgovernar e chupar a substância [ilegível] com a mira em nos afrontarem com a sua soberba e pompa, etc., etc. (BARATA, 2008, p. 843).
\end{abstract}

Mas federação é um termo muito vago, que pode conter significados bem diferentes, como argumenta Vergueiro, no debate do Senado em torno do projeto que tinha sido enviado pela Câmara. Em fala em que buscava sustentar que a federação que defendia não significava independência das províncias, o senador moderado buscou mover o debate da fixação na palavra para a consideração do conteúdo, isto é, do modo de constituição dos poderes provinciais:

(...) mas a definição desta palavra é de ser aquilo que se fizer, quando se
tratar dos poderes provinciais: não atribuo grandes coisas a esta palavra. (...)
Palavras pouco servem, mas como se devem apropriar as palavras quanto
for possível às coisas, parece-me que depois de nós tratarmos dos Poderes
Provinciais é que podemos com cabal conhecimento de causa ver se esta
palavra cabe ou não cabe. (SENADO DO IMPÉRIO DO BRAZIL, 1832, p.
229).

Entretanto, a palavra sozinha, sem definição do seu conteúdo, não era nada inofensiva, haja vista o embate em torno da denominação de "monarquia federativa" para o Império Brasileiro, que tinha sido aprovada na Câmara, mas foi rejeitada no Senado e na reunião das duas Casas da qual resultou a Lei de 12 de outubro de 1832, que estabeleceu as diretrizes da discussão da reforma de 1834 (SLEMIAN, 2006, p. 261).

A associação, no projeto de reforma da Câmara, da denominação "monarquia federativa" com a proposta de extinção da vitaliciedade do Senado, como ressalta Andréa Slemian, teve um efeito que

não deve ser minimizado. Seu aparecimento deixava à mostra que a aceleração dos acontecimentos causada pela expectativa de transformações, que em todo o Império podia ser comprovada pela generalização da instabilidade e das contestações abertas, abalou fortemente a dinâmica dos trabalhos legislativos. (...) (SLEMIAN, 2006, p. 250) ${ }^{8}$.

8 Uma amostra do grau de expectativa existente em relação à discussão da reforma proposta pela Câmara no Senado se encontra no n. 28 do Sentinela da Liberdade, de Cipriano Barata: "(...) Antes porém de entrarmos no assunto, quero dar os bom anos aos Aristocratas e Camelos, Lusitanos Madeiras e a todos os Servis traidores, lembrando-lhes que estamos no ano de 1832. Ó ano da minha alma! Tu hás de despicar-me! Tu socorrerás os que gemem inocentes, farás justiça a todos os perseguidos e salvarás a pátria! ... Eu te saúdo ano de Luzes, de glória, e de liberdade! ..." (BARATA, 2008, p. 835). 
A historiografia sobre $o$ ato adicional e os enfrentamentos entre frações liberais nos anos iniciais da regência

É possível que pelo menos parte da ameaça da denominação poderia estar justamente na sua indefinição, na qual caberiam projetos os mais diversos, inclusive aqueles que propunham ampla autonomia das províncias, pela qual chegariam a ter constituição própria.

De qualquer modo, rejeitada a denominação de "monarquia federativa", a reforma disse respeito à rearticulação entre os poderes provinciais e os poderes gerais.

Os debates de 1832, como já foi dito, desdobraram-se na elaboração da Lei de 12 de outubro desse mesmo ano, que foi a base da formulação do Ato Adicional de 1834, dois anos depois. São importantes para captarmos um momento em que existiam bastante amplas expectativas em relação à reforma da constituição, haja vista que o projeto aprovado na Câmara, e que se encontrava no Senado para ser discutido, sinalizava para mudanças que viriam a alterar profundamente a organização política do Império. Mas o cerne das questões apareceria com mais clareza no debate posterior, de 1834, cujo resultado se cristalizou no Ato Adicional.

É o que podemos ver na exposição detalhada do desdobramento das discussões feita na tese de doutoramento de Andréa Slemian, já citada. A autora faz uma apreciação meticulosa dos argumentos expostos, mostrando em minúcias como a definição dos poderes provinciais consagrada no Ato significou a vitória dos posicionamentos mais moderados, em termos de abertura para uma autonomia das províncias.

Em 1834, as expectativas quanto à reforma estariam mais contidas, haja vista as limitações da lei que estabeleceu as balizas do debate (de 12 de outubro de 1832), a qual mantivera o Senado vitalício, o Poder Moderador e excluíra a proposta de denominação do Império como "monarquia federativa". Como afirma Slemian, a expectativa nesse ano

já se encontrava mais circunscrita à forma do funcionamento políticoadministrativo do regime. O que, deve-se frisar, não era de pouca monta numa perspectiva política que privilegiava, para a eficácia do Estado, a ação do governo e de suas instituições. Por essa razão, ainda que fosse sabido que os deputados não iriam subverter a estrutura do Império como clamavam os panfletários 'exaltados' - até porque o espaço do Parlamento, como se viu, tendeu à sua preservação -, a mudança levada a cabo foi mesmo assim crucial para o sistema. (SLEMIAN, 2006, p. 262).

Foi crucial, mas ainda moderada, em termos da garantia de autonomia das províncias, em comparação com propostas que foram defendidas no plenário. Slemian (2006) sinaliza a circunscrição da esfera provincial por meio da transformação dos Conselhos Gerais em Assembleias provinciais, que significaria uma restrição maior quanto ao âmbito de atuação dos poderes provinciais, uma vez que "os órgãos existentes [os Conselhos] teriam direito de deliberar sobre todas as questões que

Revista História em Reflexão, Vol. 15, N. 29 | jan. a jun. de 2021 
A historiografia sobre $o$ ato adicional e os enfrentamentos entre frações liberais nos anos iniciais da regência considerassem necessárias para as localidades, sem marcação de qualquer limite" (SLEMIAN, 2006, p. 265). Conforme os deputados que protestaram contra essa restrição, seria clara a maior autonomia dos conselhos, em comparação com as Assembleias (SLEMIAN, 2006, p. 267).

Nos debates acerca de detalhes da definição das características e atribuições dos poderes provinciais, a autora sinaliza que existiam, na Câmara, "anseios por maiores atribuições às localidades", que foram vencidos pelas perspectivas mais "moderadas" (SLEMIAN, 2006, p. 271 e seguintes). Entretanto, faz questão de frisar que muitos dos que criticavam as propostas vitoriosas não eram da fração "exaltada", e sim da "moderada" (SLEMIAN, 2006, p. 296)‥

Entre tais detalhes que foram objeto de controvérsia, estão: a existência ou não de uma segunda Câmara nas províncias, a definição do número de deputados provinciais para a Câmara do Império, do número de deputados da assembleia provincial, o tempo de duração das legislaturas provinciais, a duração das sessões e as atribuições das Assembleias (SLEMIAN, 2006, p. 271-276).

Essas diferenças de posicionamento se expressavam claramente em entendimentos distintos sobre a articulação entre as províncias e o "centro", visões que se explicitavam no debate sobre a questão da federação:

(...) as referências a ela [federação] ainda estavam na ordem do dia. Nesse sentido, mesmo entre os mais moderados da Câmara, era comum encontrarmos defesas de uma 'federação' para o Império. (SLEMIAN, 2006, p. 278).

A perspectiva mais ampla de "federação" teria sido a apresentada por Costa Ferreira, que fez uma proposição na qual

o único elo entre as Províncias seria o da representação nacional como salvaguarda da monarquia. O mesmo deputado chegou a falar na necessidade de 'uma verdadeira reforma' e a ameaçar que, se os 'senhores centralizadores' teimassem em submeter as províncias do Norte, alguma 'desordem' poderia acontecer (SLEMIAN, 2006, p. 279-280).

Em contraposição, José Custódio Dias e Bernardo Pereira de Vasconcelos rejeitaram claramente a "federação" (SLEMIAN, 2006, p. 279-280).

No debate que se travou acerca do poder dos presidentes e de sua relação com a Assembleia e com o conselho de presidência, mais uma vez as posições se polarizaram. Na discussão de proposta de criação de conselho presidencial eletivo, e com voto não apenas consultivo, mas também deliberativo, havia aqueles que, como Costa Ferreira, argumentavam que os presidentes "eram responsáveis por centralizar o poder nas Províncias", enquanto outros, como Evaristo da Veiga, defenderiam os presidentes como "expressão da província" e também da "vontade nacional" (SLEMIAN, 2006, p. 284).

9 Neste ponto, a posição da autora se diferencia da de Basile (2009, p. 53-119), que destaca a oposição "exaltada" durante os debates de 1834. 
Além de não passarem medidas tendentes a diminuir o poder ou a tornar eletivo o presidente de província (foi proposta eleição por lista tríplice), depois da aprovação da Lei de 12 de agosto de 1834, foi aprovado um regimento da presidência que tinha sido enviado para a Câmara pelo Senado (SLEMIAN, 2006, p. 297), em que foram feitas inserções que implicavam um aumento do poder daquela autoridade:

(...) duas inserções feitas pelos deputados reforçavam o sentido da autoridade presidencial. A primeira, a extinção do Conselho de Presidência; e a segunda, de um parágrafo que atribuía ao mesmo presidente o poder temporário de decidir sobre conflitos de jurisdição, entre as autoridades da Província. Ambas deixavam claro que o 'delegado do Imperador' poderia agir individualmente, sem consulta prévia a nenhuma instância, o que incluía a centralização, na sua figura, da mediação das tensões administrativas. Dessa forma, um dos principais papéis de árbitro que anteriormente ele desempenhava em comunhão com seus conselheiros, conforme vimos anteriormente, ficaria restrito, a partir de então, a si mesmo. (SLEMIAN, 2006, p. 298).

Como podemos notar, a partir da consideração da documentação, e também da bibliografia que trata do período, houve grandes expectativas (visível nos textos de Cipriano Barata, e nos Anais do Senado, principalmente) em relação à elaboração do Ato Adicional, que terminou por promover um tipo de reorganização dos poderes provinciais que significava o atendimento apenas parcial de reivindicações dos chamados "exaltados" e a incorporação delas num processo de descentralização que tinha sentidos nuançados. Isso dificulta a adesão a uma representação do Ato como marco inequívoco e unívoco da ampliação das "liberdades provinciais" no Império.

Conforme a boa síntese de Marcello Basile a respeito do Ato Adicional, este não teria contemplado a federação reivindicada pelos exaltados, e sim uma descentralização administrativa, e com veto à autonomia municipal:

Promulgado a 12 de agosto de 1834, o ato adicional à Constituição extinguia o Conselho de Estado, substituía a Regência Trina pela Uma (com regente eleito, a cada quatro anos, por voto secreto e direto) e criava assembleias legislativas nas províncias (com legislaturas bienais); a elas competia legislar sobre diversos assuntos, como fixação das despesas provinciais e municipais, impostos provinciais, repartição da contribuição direta pelos municípios, fiscalização das rendas e das despesas municipais e provinciais, nomeação dos funcionários públicos, policiamento e segurança pública, instrução pública e obras públicas, ficando as resoluções da Assembleia sujeitas à sanção do presidente de província. Se não estabelecia propriamente uma federação, já que continuavam os presidentes a ser escolhidos pelo poder central e as províncias impedidas de ter Constituições próprias, o ato adicional descentralizou a administração e conferiu mais autonomia às províncias, com a criação das assembleias provinciais e a divisão das rendas públicas. Todavia, a autonomia municipal foi vetada, havendo forte concentração administrativa no âmbito provincial, o que fazia com que quase toda a economia dos municípios dependesse das assembleias provinciais. Com a eleição periódica para regente uno configurava-se a chamada 'experiência republicana', posto que atrelada a instituições e valores monárquicos. (BASILE, 2009, p. 81).

Basile (2009) destaca a persistência da oposição exaltada (votos contrários de Antonio Ferreira França e seus filhos Ernesto e Cornélio, e abstenção de Henriques de Rezende e Lino Coutinho) (BASILE, 2009, p. 82) e o seu insucesso nas eleições 
subsequentes (Idem, p. 111). Mas também sinaliza um fortalecimento dos poderes provinciais. Esse fortalecimento teria sido um dos fatores que teriam desgastado o governo de Feijó como Regente:

O segundo grande fator de desgaste do governo foi a desilusão com as reformas liberais. Se elas foram a expressão do predomínio político moderado, as transformações que operaram colocaram em xeque essa própria posição. Por meio delas, houve notável fortalecimento dos poderes provinciais, que passaram a dispor de grande parte dos instrumentos garantidores da ordem, sem que estivessem, todavia, bem afinados com os interesses do governo central. Os problemas, assim, não tardaram a aparecer, e com eles vieram as críticas e desilusões em relação às mudanças operadas. Nessas circunstâncias, as legislaturas de 1834-1837 e 1838-1841 terão como um de seus principais traços o intuito de reformar a obra da legislatura que as antecedeu. (BASILE, 2009, p. 86).

Carlos Eduardo Ferreira França, a partir da pesquisa feita com jornais paulistas, considera que a ideia de efetivação de uma ruptura pelo Ato Adicional precisa ser suavizada com a observação do significado político já adquirido anteriormente pelos Conselhos Provinciais, que foram substituídos pelas Assembleias Provinciais. O Ato Adicional teria significado um alargamento, em razão do poder legislativo dessas Assembleias, mas isso teria sido contrabalançado pelo regimento para os presidentes das províncias, que foi aprovado logo depois, e que significou um fortalecimento do presidente (em virtude da supressão dos conselhos de presidência e da mudança da escolha do vice-presidente, que deixou de ser o primeiro conselheiro mais votado e passou a ser de escolha do ministro do Império) e, desse modo, da presença do executivo central na província (OLIVEIRA, 2009, p. 357).

Também é relativizado o significado descentralizador do Ato Adicional pela centralização do controle dos rendimentos das províncias resultante da Lei de 24 de outubro de 1832, que teria classificado as rendas do Império em "gerais" e "provinciais"10. Mas França de Oliveira também relativiza o significado dessa centralização, ao dizer que a organização futura da estrutura financeira imperial implicou a constituição de um aparelhamento que garantia alguma autonomia:

(...) a ação legislativa que se consubstanciou nas primeiras leis do orçamento, na criação do Tribunal do Tesouro Público Nacional, nas Tesourarias Provinciais e na divisão de recursos dos cofres públicos lançava luz para o fato de que qualquer passo a ser dado no sentido de estabelecer uma normalização da máquina pública imperial acarretaria num aparelhamento jurídico-administrativo das províncias. Assim, a questão não recaía apenas sobre o aumento do nível de participação das províncias no manejo das suas contas, mas também sobre a necessidade dos políticos do Império reconhecerem que esse somente lograria como um estado monárquicoconstitucional caso fossem criados mecanismos político-administrativos adequados à realidade das províncias, e que garantissem aos poderes locais uma certa margem de autonomia para geri-los. (OLIVEIRA, 2009, p. 345346).

10 Discutida por Maria de Lourdes Viana Lyra, conforme citada em Basile (2009, p. 110), e em Oliveira (2009, p. 341). 


\section{Considerações finais}

O percurso realizado neste artigo permite notar que pesquisas feitas em nosso século, com base em exploração minuciosa das fontes, têm contribuído para nuançar bastante a sinalização de um marco divisório da história do Império no Ato Adicional de 1834, especialmente em relação ao grau de autonomia que ele teria proporcionado aos poderes locais, marco este presente em autores que trataram da história do Império por meio de grandes sínteses, baseadas em boa medida em textos produzidos por políticos diretamente envolvidos nas lutas políticas do século XIX, e a quem, em diversas circunstâncias, interessava colocar o Ato como expressão máxima de descentralização (Teófilo Ottoni, Timandro, Justiniano José da Rocha, Tavares Bastos). Trata-se de um comprometimento entre a escrita da história e determinada memória do passado Imperial que visava definir a interpretação a ser dada a um contexto multifacetado, obscurecendo a luta política de que resultou uma forma de organização político-administrativa excludente das propostas de frações mais radicais entre os liberais.

As fontes e a bibliografia recente que exploramos neste texto contribuem para a constituição de uma história do Ato Adicional não aderida a tais formulações alicerçadas em leituras carregadas de instrumentalização da memória política.

\section{Fontes e bibliografia}

Fonte manuscrita:

COLEÇÃO TAVARES BASTOS. Seção de Manuscritos da Biblioteca Nacional, códice 1.03.33.12, p. 8.

Fontes impressas:

SENADO DO IMPÉRIO DO BRAZIL. Sessão de 4 de junho (transcrição). In: Annaes do Senado do Imperio do Brazil: anno de 1832. Brasília: Secretaria Especial de Editoração e Publicações/Subsecretaria de Anais do Senado Federal, [201-?], Livro 1. p. 228-229. Disponível em: https://www.senado.leg.br/publicacoes/anais/pdf/Anais_ Imperio/1832/1832\%20Livro\%201.pdf. Acesso em: 30 nov. 2020.

AURORA FLUMINENSE (1827-1839). Rio de Janeiro: Typographia de R. Ogier, n. 591 , p. 2507,10 fev. 1832. Disponível em: http://memoria.bn.br/pdf/706795/ per706795_1832_00591.pdf. Acesso em: 30 nov. 2020.

O REPÚBLICO (RJ). Rio de Janeiro, 1830-1855.

30 de junho de 1832, n. 168, p. 603.

6 de novembro de 1832, n. 207, p. 769.

Disponível em: http://bndigital.bn.br/acervo-digital/republico/332704. Acesso em: 30 nov. 2020. 
Referências bibliográficas

ABREU, Eide Sandra Azevedo. O evangelho do comércio universal: Tavares Bastos e as tramas da Liga Progressista e do Partido Liberal (1861-1872). São Paulo: Annablume; Fapesp, 2011.

BARATA, Cipriano. Sentinela da liberdade e outros escritos. Organização e edição por Marco Morel. São Paulo: Editora da Universidade de São Paulo, 2008.

BASILE, Marcello. O laboratório da nação: a era regencial (1831-1840). In: GRINBERG, Keila; SALLES, Ricardo (org.). O Brasil imperial: v. 2 (1831-1870). Rio de Janeiro: Civilização Brasileira, 2009.

BASTOS, Aureliano Cândido Tavares. A província. Estudo sobre a descentralização no Brasil. 2. ed. feita sobre a $1^{a}$ edição de 1870. São Paulo, Rio de Janeiro, Recife: Cia. Ed. Nacional, 1937.

BEIGUELMAN, Paula. Formação política do Brasil. São Paulo: Pioneira, 1967.

CARVALHO, José Murilo de. A construção da ordem: a formação da elite política imperial. Rio de Janeiro: Campus, 1981.

CASTRO, Paulo Pereira de. A "experiência republicana", 1831-1840. In: HOLANDA, Sérgio Buarque de (dir.). História geral da civilização brasileira. São Paulo: Difel, 1967. T. II, v. 2, p. 9-67.

FERREIRA, Gabriela Nunes. Centralização e descentralização no Império. O debate entre Tavares Bastos e Visconde de Uruguai. São Paulo: Departamento de Ciência Política da Universidade de São Paulo; Editora 34, 1999.

LEAL, Victor Nunes. Coronelismo, enxada e voto: o município e o regime representativo no Brasil. 3. ed. Rio de Janeiro: Editora Nova Fronteira, 1997.

MAGALHÃES JÚNIOR, Raimundo. Três panfletários do Segundo Reinado. São Paulo: Nacional, 1956.

MARSON, Izabel Andrade. O império da revolução: matrizes interpretativas dos conflitos da sociedade monárquica. In: FREITAS, Marcos César de (org.). Historiografia brasileira em perspectiva. São Paulo: Contexto, 1998, p. 74.)

MARX, Karl. O 18 Brumário de Luís Bonaparte. In: Manuscritos econômicofilosóficos e outros textos escolhidos. 2. ed. São Paulo: Abril Cultural, 1978.

MATTOS, Ilmar R. de. O tempo saquarema. São Paulo: Hucitec/Brasília: INL, 1987. 
OLIVEIRA, Carlos Eduardo França de. Poder local e palavra impressa: a dinâmica política em torno dos Conselhos Provinciais e da imprensa periódica em São Paulo, 1824-1834. 2009. Dissertação (Mestrado em História) - Faculdade de Filosofia, Letras e Ciências Humanas, Universidade de São Paulo, São Paulo, 2009.

OTONI, Teófilo. Circulares de Teófilo Otoni aos eleitores de senadores de Minas Gerais (1860). In: BONAVIDES, Paulo; AMARAL, Roberto. Textos políticos da História do Brasil: volume 2 - Segundo Reinado (1840-1889). Brasília: Senado Federal, Subsecretaria de Edições Técnicas, 1996. p. 197-313.

ROCHA, Justiniano José da. Ação, Reação, Transação. In: MAGALHÃES Jr., R. Três panfletários do Segundo Reinado. São Paulo: Cia. Editora Nacional, 1956. p. 161218.

SILVA, Lígia Maria Osório. O federalismo de Tavares Bastos e de Campos Sales: elementos para um ensaio comparativo. In: REIS, Elisa; ALMEIDA, Maria Hermínia Tavares de; FRY, Peter (org.). Política e cultura: visões do passado e perspectivas contemporâneas. São Paulo: ANPOCS/HUCITEC, 1996. p. 75-90.

SLEMIAN, Andréa. Sob o império das leis: Constituição e unidade nacional na formação do Brasil (1822-1834). 2006. Tese (Doutorado em História Social) Faculdade de Filosofia, Letras e Ciências Humanas, Universidade de São Paulo, São Paulo, 2006. Disponível em: https://www.teses.usp.br/teses/disponiveis/8/8138/tde13072007-114942/publico/TESE_ANDREA_SLEMIAN.pdf. Acesso em: 30 nov. 2020.

TASINAFO, Célio Ricardo. Relatório Científico II - Bolsa Doutorado no País da Fundação de Amparo à Pesquisa do Estado de São Paulo. Processo 00/13307-7. Campinas, janeiro de 2003.

TORRES HOMEM, Francisco de Sales. O libelo do povo. In: MAGALHÃES JÚNIOR., R. Três panfletários do Segundo Reinado. São Paulo: Nacional, 1956. p. 45-126.

Recebido em fevereiro de 2020.

Aprovado para publicação em dezembro de 2020. 